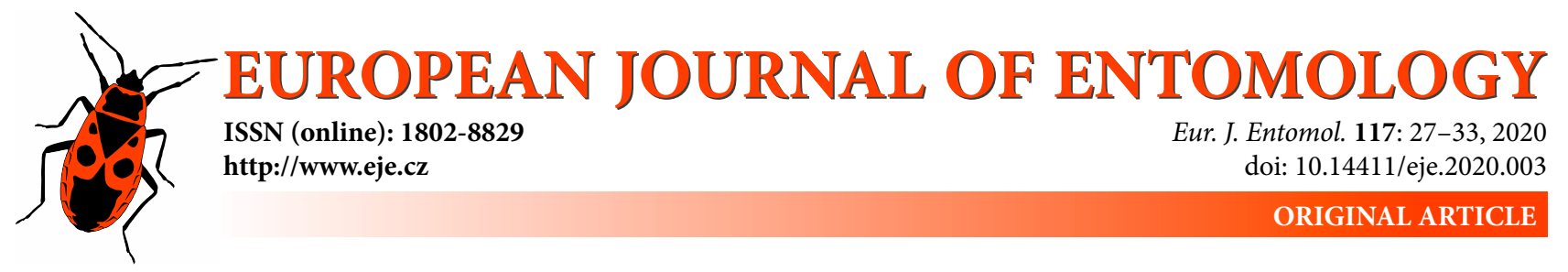

\title{
Phenotypic diversity in red wood ants (Hymenoptera: Formicidae): Is kinship involved?
}

\section{OKSANA SKALDINA and JounI SORVARI}

Department of Environmental and Biological Sciences, University of Eastern Finland, P.O. Box 1627, FI-70211 Kuopio, Finland; e-mails: oksana.skaldina@uef.fi, jouni.sorvari@uef.fi

Key words. Formicidae, Formica rufa, colouration, genotype-by-environment interactions, melanisation, relatedness, polyphenism

\begin{abstract}
Phenotypic diversity depends on genotype diversity, but the degree of genotype-by-environment interaction is speciesspecific. Red wood ants (Formica s. str) are keystone species in boreal forests and very variable phenotypically. These variations are used for species identification and proposed as ecological indicators of anthropogenic disturbances. However, their origin is unknown. Here we aimed to provide a preliminary answer to this question and outline the direction for future research. We determined the interrelation between nest mate worker relatedness (kinship) and the diversity of colour morphs, degree of melanisation and size of the red wood ant, Formica rufa. In Finnish populations of this species polyandry, which involves multiple mating by queens is the principal determinant of the relatedness between workers. We hypothesised, that if phenotypic diversity is a result of genetic diversity, then polyandrous colonies should produce more phenotypically diverse workers. A total of 336 individuals belonging to 20 colonies were used for this study. We collected ants from coniferous and broadleaf forests in Finland, fixed them in $96 \%$ alcohol, then digitally photographed, genotyped and analysed the phenotypic variation. The average colony nest mate worker relatedness was used as an estimate of the level of polyandry (more than one if $r<0.6$ ). Our results revealed no associations between the diversity of the phenotypic traits measured and worker kinship in F. rufa. As a further step to reveal the degree of genotype-by-environment interaction in determining the colour traits of the red wood ant we suggest more sophisticated genetic studies indicating the heritability of phenotypic traits between patrilinies and testing of environmental factors such as temperature, humidity, UV-radiation, food and pollution.
\end{abstract}

\section{INTRODUCTION}

Phenotypic diversity is ubiquitous. Insects vary in size, shape and colouration, so even within a single species extreme variations may exist (Wetterer, 1999). Genes control an entire phenotype or a single morph, producing variation in polymorphism (Forsman, 2016). Likewise, identical genotypes can develop into distinct morphs, which is called polyphenism (Simpson et al., 2011). Consequently, phenotypically diverse and polymorphic species differ in the degree of their genotype-by-environment interactions.

It was previously assumed, that polyphenism produced castes of social insects, one of the most striking examples of variability among animals (Hölldobler \& Wilson, 1990; Simpson et al., 2012). A caste comprises all the individuals, engaged in a certain type of operation. Males originate from haploid eggs and females from diploid eggs. Females have the potential to develop into reproductive individuals (queens) or non-reproductive individuals, workers. Workers undergo further specialisation and develop into morphological or behavioural castes, performing different tasks, such as brood nursing, grooming, nest building, defending the colony and foraging. Phenotypic variations, varying from barely visible to highly conspicuous variations, accompany this division of labour.

It has been known for a long time for ants (Hymenoptera: Formicidae) that non-genetic factors trigger a cascade of hormonal reactions, regulating caste specification and associated phenotypic diversity (Hölldobler \& Wilson, 1990). However, more recent studies confirm the decisive role of genetics in some species (Ross \& Keller, 1998; Hughes et al., 2003; Bargum et al., 2004; Jaffe et al., 2007; Smith et al., 2008a, b), but not in others (Leniaud et al., 2015). Finally, the division of labour and phenotypic variability in ants vary along a continuum ranging from environmental caste determination (ECD) to genetic caste determination (GCD) (Schwander et al., 2010; Libbrecht et al., 2013). There are numerous studies on the genotype-byenvironment interaction related to the phenotypic diversity in the size and shape of ants (Wilson, 1953; Davidson, 1978; Porter \& Tschinkel, 1985; Chapuisat \& Keller, 2002; Hughes et al., 2003; Schwander et al., 2005; Smith et al., 2008a; Leniaud et al., 2015). However, the role of genetic versus environmental factors in determining ant colouration is not clear. 
In phenotypically variable species of ants such as red wood ants (Formica s. str) colour provides essential information for identifying species (Stockan et al., 2016) and has been proposed as an ecological and environmental indicator for evaluating deforestation (Skaldina \& Sorvari, 2017b) and heavy metal pollution (Skaldina et al., 2018). Other phenotypic characteristics, such as size, hairiness and the symmetry of the petiole node in red wood ants might also be useful traits for monitoring habitat degradation (Fedoseeva, 2011). The colouration on the head and pronotum of Formica rufa L. is polymorphic, which indicates it is possible to detect a level of modularity and size-dependence in some colour traits (Skaldina \& Sorvari, 2017a). However, evidence for a genotype-by-environment interaction determining colouration within the red wood ant group is still scarce.

As an initial step in developing this research we here investigate whether relatedness (kinship, $r$ ) between red wood ant workers affects their phenotypic characteristics, such as, colour morph, degree of melanisation and size. Generally, in insects, there is evidence for genetic preconditioning for both colour morph (Kunte et al., 2014) and cuticular melanisation (Roff \& Fairbairn, 2013). In addition, in some species there is a genetic correlation between colour pattern and body size (Ahnesjö \& Forsman, 2003). We predict that if some genetic factors have a strong effect on red wood ant phenotypes, then closely related individuals might share similar phenotypic traits and those with a low degree of kinship might demonstrate higher phenotypic diversity because of their genetic diversity. We chose to test this using the red wood ant, Formica rufa, as Finnish populations of this species are mainly monogynous (each colony typically has one reproductive queen) and vary from monandrous to polyandrous (Rosengren et al., 1993). Monandrous queen workers are highly related to their full sisters, which have the same genes, however in polyandrous colonies relatedness is lower (Pamilo et al., 2016). Thus, polyandry principally regulates the average nest mate worker relatedness and complexity of family structure in this species. Revealing possible interrelations between the complexity of family structure: simple (higher $r$ ) or complex (lower $r$ ) and phenotypic diversity (regarding colouration) will shed light on the species systematics and determine the direction of future research.

\section{MATERIALS AND METHODS}

\section{Study species}

In ant societies, the primary ways of increasing genotype diversity are polygyny, which involves multiple queens, and polyandry which involves multiple mating by queens (Keller \& Reeve, 1994; Heinze, 2008). In natural habitats in Central and Northern Europe, red wood ant, F. rufa, mainly have monodomous and monogynous social structures. However, this species can shift to polydomy and polygyny in isolated and fragmented landscapes in some parts of Europe (Dekoninck et al., 2015). This shift usually occurs in patches that differ in their management, vegetation characteristics or degree of isolation (Gyllenstrand et al., 2004). In Finland, F. rufa is mainly monogynous, varying from monandrous to polyandrous. Thus, polyandry principally regulates the average nest mate worker relatedness and complexity of the family structure in this species.

\section{Sample size and study area}

Red wood ant, F. rufa, workers $(\mathrm{n}=336)$ were collected by random sampling in May 2012 in the vicinity of the south western Finnish city of Turku $\left(60.42^{\circ}, 22.27^{\circ}\right)$. From 10 to 30 individuals (mean \pm SD: $16.8 \pm 4.2$ individuals per nest) were collected from the tops of nest mounds $(n=20)$. All the colonies typically occupied separate forest stands and were checked for monodomy using visual observations and behavioural tests. All nests studied were monodomous. The ant mounds were found in either patches of coniferous forest, where the dominating species of trees were Norway spruce (Picea abies) and Scots pine (Pinus sylvestris), or in broadleaf oak (Quercus robur) forest.

\section{Morphometrics and colour pattern analyses}

We separated the heads and thoraxes and photographed them independently on a millimetre paper background using an Olympus SZ40 digital stereo microscope and DeltaPix Invenio 3S 3 Mpixel CMOS camera with a magnification of X 40 for the head and $X 25$ for the thorax. The photographs were further processed with Delta Pix Viewer LE, Adobe Photoshop CS5 and ImageJ software. The maximum width of the head above the eyes was used as an estimate of an individual's body size (Sorvari \& Hakkarainen, 2009). The thorax length was taken as an additional morphometric parameter. These measurements were done using ImageJ software, with the scale set to $1 \mathrm{~mm}$.

Colour variations (morphs) and the degree of cuticular melanisation (MD) were assessed as described by Skaldina \& Sorvari (2017a). By using a threshold approach, we revealed nine types of morphs in terms of the head and eight in terms of the pronotum. We measured the degree of melanisation (MD) on standardised rectangle areas on the face, and the oval area on the dorsal part of the pronotum. In the ImageJ computer program, the MD was scaled from grey to absolute grey with values of 0 (totally white) to 255 (totally black). We used the diversity in phenotypic variation in the colour morphs, the degree of melanisation and the size of $F$. rufa (Fig. 1) to assess their possible interrelations, as well as the relatedness between workers, and complexity of the structure of the family.

\section{Genetic analyses}

Of the workers sampled, eight to ten individuals of different sizes and colour morphs from each nest were genotyped. DNA was extracted using the salt extraction method of Aljanabi \&

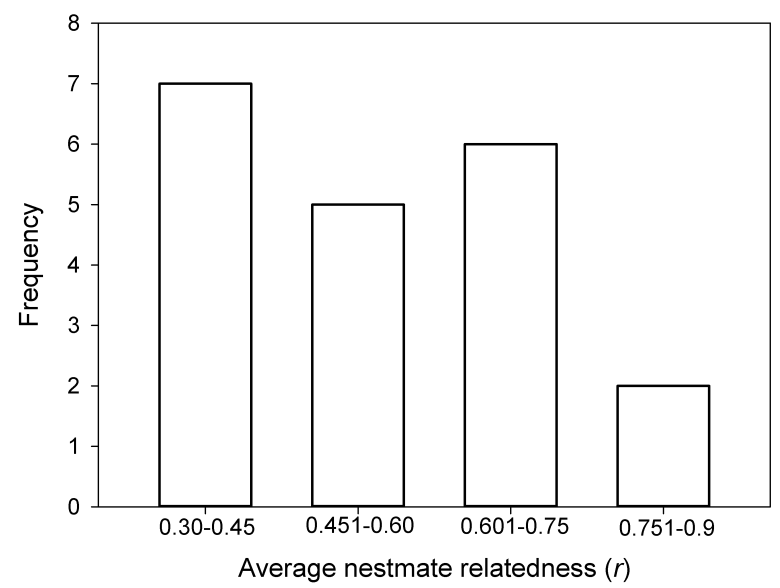

Fig. 1. Distribution of nest mate relatedness across nests $(N=20)$ of Formica rufa, in Southwest Finland. 


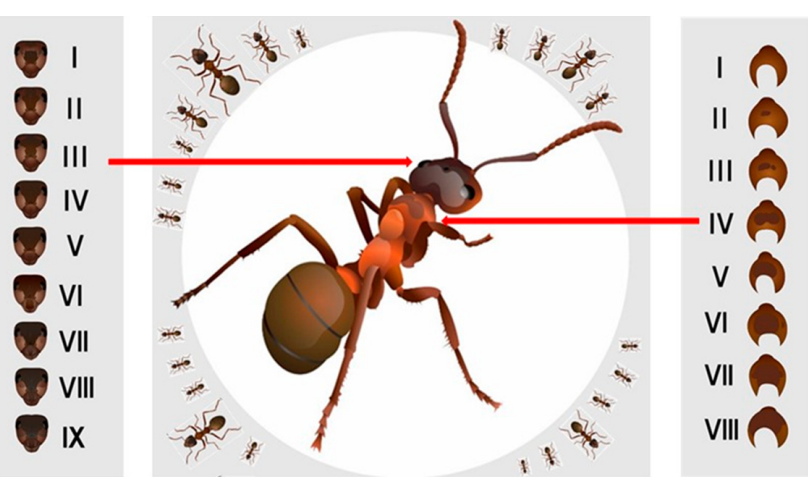

Fig. 2. Phenotypic diversity of red wood ants $F$. rufa in terms of the size, the head and pronotum colour morph differentiation and degree of melanisation as described in detail in Skaldina \& Sorvari (2017a).

Martinez (1997) with small modifications (volumes were adjusted for the ant samples). All samples were genotyped with 10 markers divided into 2 multiplexes (MPs). MP1 consisted of the following markers: FE-42, FE-7, FE-19, FE-38 (Gyllenstrand et al., 2002), FL-21 and FL-12 (Chapuisat, 1996). MP2 consisted of the following markers: FE-17, FE-8 FE-13 and FE-37 (Gyllenstrand et al., 2002).

Amplification was carried out in two $10-\mu 1$ reactions consisting of ca. $40 \mathrm{ng}$ of DNA, 0.05 to $0.4 \mu \mathrm{M}$ of each primer and $1 \mathrm{X}$ a Qiagen multiplex PCR master mix (Qiagen Inc. Valencia, CA, USA). The PCR profile used followed the manufacturer's standard protocol with annealing temperatures of $58^{\circ} \mathrm{C}$ for both MPs. The amplifications were performed on C1000 TouchTM (BIO-RAD) and S1000TM (BIO-RAD) thermal cyclers. For electrophoresis, the PCR products were pooled ( $1 \mu 1$ of MP1, $2 \mu 1$ of MP2) and diluted with $100 \mu \mathrm{l}$ of sterile water. $2 \mu \mathrm{l}$ of the pooled and diluted PCR product was combined with GS600LIZ Size Standard (Applied Biosystems) and HiDi-formamide (Applied Biosystems).
The samples were denatured at $95^{\circ} \mathrm{C}$ for five minutes and the size of the fragments was determined by capillary electrophoresis on an ABI PrismTM 3130xl genetic analysis instrument.

The genotypes were scored using GENEMARKER version 2.2.0 (SoftGenetics) and following visual inspection, exported to a spreadsheet program for downstream analyses. The average relatedness $(r)$ between the nest mate workers and allele frequencies were estimated using the GenAlEx 6.5 macro for Microsoft Excel (Peakall \& Smouse, 2012). In this study the colony was categorized as polyandrous if $r<0.6$. Generally, in red wood ants if $r=0.75$ then the workers are considered to be full sisters (Pamilo et al., 2016). The value $r<0.6$ corresponds to an effective number of mating's of 1.43 (Pamilo, 1993). Therefore, it was selected as a threshold.

\section{Statistics}

We used SAS 9.4 statistical software (SAS Institute Inc.) for statistical analyses. Two types of predictor variables were used in the analyses: (i) continuous, which was the average nest mate worker relatedness, (ii) categorical, which was the structure of the family (simple when there was one father, and complex when there was more than one). Linear Mixed Model (LMM) analyses was performed with the nest as a random factor when we analysed the effect of worker kinship on continuous phenotypic traits. Individuals that originated from the same nest might share similar environmental conditions, therefore we included nest as a random factor in the model. Generalized Linear Model (GLM, the procedure GENMOD) was used for counts (Poisson distribution with Log link: $\left.\mathrm{GLM}_{\text {POISSON }}\right)$. We also calculated the intracolony colour morph diversity (Shannon) and evenness indices. The Shannon diversity index was calculated using EstimateS 9.1 (Colwell, 2013) software and the evenness index with Microsoft Excel. Due to the relative low number of replicates $(\mathrm{N}=20)$ we carried out simple post-hoc power analyses of the comparisons between simple (monandry) and complex (polyandry) family types using web-based power calculator for two-samples and two-sided equality data (available at powerandsamplesize.com/calculators).

Table 1. Colony-level data for the colonies of Formica rufa studied: average colony worker-worker relatedness ( $r$ ), family type suggested by $r(1$ - monandry, 2 - polyandry), head width with coefficient of variation (Hw, mm, CV) and thorax length with coefficient of variation (Thl, mm, CV), number of head and pronotum (Pn) colour morphs with the number of workers studied in brackets, the Shannon diversity, and evenness indices of the head and pronotum colour morphs.

\begin{tabular}{|c|c|c|c|c|c|c|c|c|c|c|c|c|c|c|}
\hline \multirow{2}{*}{ Nest } & \multirow{2}{*}{$r$} & \multirow{2}{*}{$\begin{array}{c}\text { Family } \\
\text { type }\end{array}$} & \multicolumn{2}{|c|}{$\mathrm{Hw}$} & \multicolumn{2}{|c|}{ Thl } & \multicolumn{2}{|c|}{ Morph N } & \multicolumn{2}{|c|}{ MD } & \multicolumn{2}{|c|}{ Diversity } & \multicolumn{2}{|c|}{ Evenness } \\
\hline & & & $\mathrm{mm}$ & $\mathrm{CV}$ & $\mathrm{mm}$ & $\mathrm{CV}$ & Head & $P n$ & Frons & $\mathrm{Pn}$ & Head & $\mathrm{Pn}$ & Head & $\mathrm{Pn}$ \\
\hline 1 & 0.363 & 2 & 1.96 & 0.13 & 2.70 & 0.10 & $4(18)$ & $4(18)$ & 195.41 & 194.47 & 0.76 & 1.13 & 0.55 & 0.82 \\
\hline 2 & 0.720 & 1 & 1.96 & 0.15 & 2.68 & 0.11 & 6 (19) & $6(18)$ & 197.93 & 188.91 & 1.00 & 0.70 & 0.56 & 0.39 \\
\hline 3 & 0.624 & 1 & 1.90 & 0.14 & 2.54 & 0.13 & $5(23)$ & $5(23)$ & 196.18 & 188.11 & 1.24 & 0.84 & 0.90 & 0.52 \\
\hline 4 & 0.436 & 2 & 1.51 & 0.13 & 2.12 & 0.11 & $2(28)$ & $4(26)$ & 194.12 & 199.66 & 0.67 & 2.04 & 0.97 & 1.47 \\
\hline 5 & 0.548 & 2 & 1.78 & 0.12 & 2.43 & 0.12 & 3 (19) & $3(18)$ & 193.82 & 194.96 & 0.82 & 1.12 & 0.75 & 1.02 \\
\hline 6 & 0.724 & 1 & 2.06 & 0.07 & 2.73 & 0.07 & $3(17)$ & $2(17)$ & 193.53 & 190.24 & 0.85 & 1.57 & 0.77 & 2.27 \\
\hline 7 & 0.631 & 1 & 1.91 & 0.11 & 2.61 & 0.11 & $4(13)$ & $4(13)$ & 196.09 & 194.67 & 1.07 & 1.41 & 0.77 & 1.02 \\
\hline 8 & 0.567 & 2 & 1.92 & 0.09 & 2.48 & 0.08 & 5 (14) & $2(13)$ & 193.18 & 194.82 & 1.13 & 1.47 & 0.70 & 2.12 \\
\hline 9 & 0.431 & 2 & 1.94 & 0.10 & 2.60 & 0.09 & $3(12)$ & $3(11)$ & 194.95 & 190.03 & 0.89 & 1.66 & 0.81 & 1.51 \\
\hline 10 & 0.433 & 2 & 2.06 & 0.06 & 2.67 & 0.08 & 2 (12) & $2(9)$ & 198.13 & 191.33 & 0.45 & 3.24 & 0.65 & 4.68 \\
\hline 11 & 0.790 & 1 & 2.02 & 0.05 & 2.63 & 0.05 & $3(14)$ & $3(14)$ & 194.77 & 186.81 & 0.90 & 1.25 & 0.82 & 1.14 \\
\hline 12 & 0.850 & 1 & 2.02 & 0.06 & 2.65 & 0.07 & $2(13)$ & $2(13)$ & 197.51 & 192.61 & 0.67 & 0.95 & 0.96 & 1.37 \\
\hline 13 & 0.594 & 2 & 1.96 & 0.06 & 2.56 & 0.05 & $4(13)$ & $3(12)$ & 195.29 & 195.17 & 1.07 & 1.36 & 0.77 & 1.23 \\
\hline 14 & 0.440 & 2 & 1.99 & 0.10 & 2.80 & 0.11 & $6(14)$ & $4(14)$ & 194.59 & 191.37 & 1.67 & 0.79 & 0.93 & 0.57 \\
\hline 15 & 0.602 & 1 & 1.92 & 0.13 & 2.63 & 0.08 & $4(15)$ & $2(15)$ & 194.36 & 193.14 & 0.95 & 3.71 & 0.69 & 5.35 \\
\hline 16 & 0.508 & 2 & 1.75 & 0.10 & 2.21 & 0.08 & $4(22)$ & $3(22)$ & 199.14 & 190.13 & 0.66 & 1.22 & 0.48 & 1.11 \\
\hline 17 & 0.389 & 2 & 1.94 & 0.09 & 2.51 & 0.09 & $3(14)$ & $4(14)$ & 195.94 & 192.33 & 0.90 & 2.25 & 0.82 & 1.62 \\
\hline 18 & 0.444 & 2 & 1.96 & 0.07 & 2.67 & 0.05 & $3(18)$ & $3(18)$ & 194.33 & 194.40 & 0.94 & 2.36 & 0.85 & 2.15 \\
\hline 19 & 0.490 & 2 & 1.67 & 0.14 & 2.11 & 0.13 & $5(20)$ & $5(20)$ & 195.91 & 191.80 & 1.26 & 1.40 & 0.78 & 0.87 \\
\hline 20 & 0.660 & 1 & 1.88 & 0.09 & 2.50 & 0.10 & $5(16)$ & $4(16)$ & 197.30 & 195.56 & 1.46 & 0.91 & 0.91 & 0.66 \\
\hline
\end{tabular}



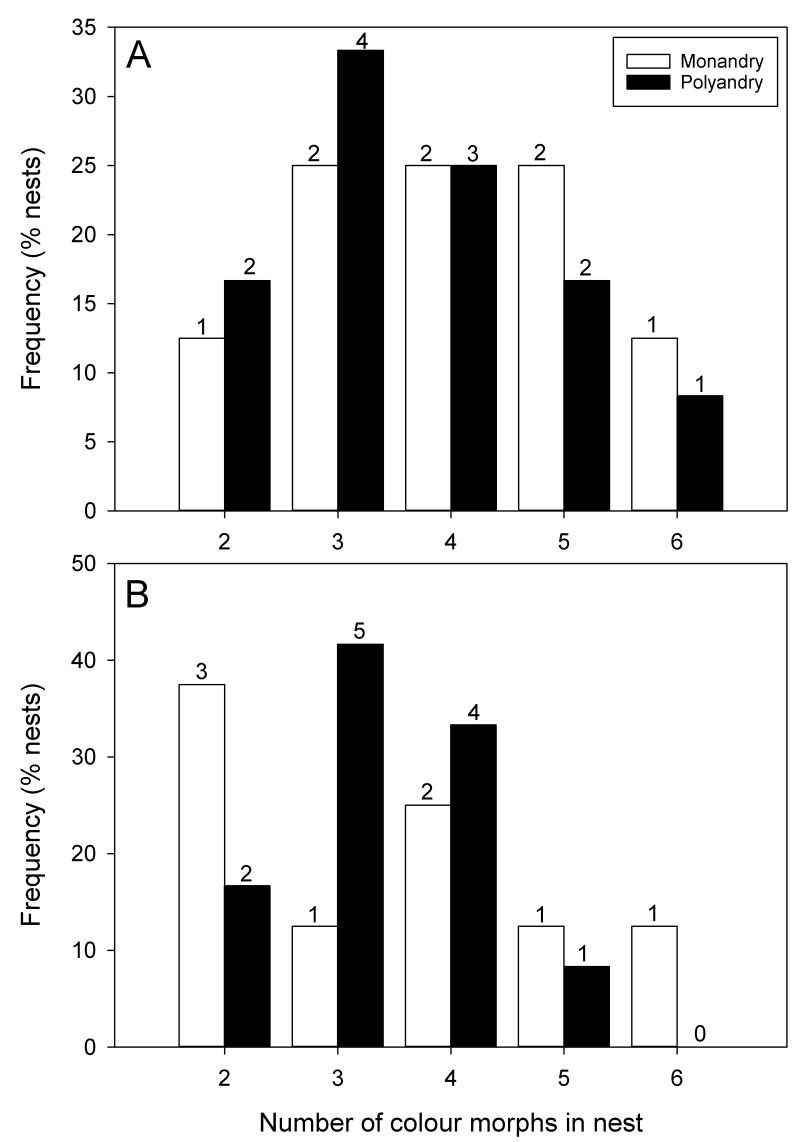

Fig. 3. Colour morph frequencies of the head (A) and pronotum (B) in colonies classified as monandrous and polyandrous based on their intranest worker-to-worker relatedness. Numbers above bars are the number of colonies.

\section{RESULTS}

We found variations in nest mate worker kinship (relatedness), distribution of head-pronotum colour morphs, degree of melanisation and worker body size in all the F. rufa colonies studied (Table 1). The worker-to-worker nest mate relatedness estimates varied from 0.363 to 0.850 (mean \pm SD: $0.562 \pm 0.138$; Fig. 2). The mean relatedness estimate of the population deviated significantly from 0.75 (one-sample t-test, $\mathrm{df}=19, t=-6.07, P<0.0001$ ) indicating that there was substantial variation in the complexity of the structure of the family in the colonies. Eight colonies were categorised with a high degree of kinship between the workers $(r>0.6$; presumably one father and simple family structure) and 12 were categorised with a low level of kinship $(r<0.6$; two or more fathers and complex family structure).

Several colour morphs (Mean \pm SD: head: $3.8 \pm 1.23$; pronotum: $3.4 \pm 1.14$ ) were present within a colony, with the highest number of six colour morphs per colony for both head and pronotum. While the number of colonies studied was relatively low, the frequency of head colour morphs in colonies with simple and complex family structures were very similar; however, the frequency of different pronotum colour morphs was more variable between the family types (Fig. 3). Within a colony, the total number of head colour morphs positively correlated with the number of pronotum colour morphs $(r=0.58, P=0.007)$. Individual head size (nest mean Hw) and variation in worker head size (coefficient of variation value of colony) were not associated with the head colour morph frequencies $\left(\mathrm{GLM}_{\text {POISSON }}\right.$, nest mean Hw: $\mathrm{df}=1, \chi^{2}=2.64, P=0.104$; Hw coefficient of variation: $\left.\mathrm{df}=1, \chi^{2}=0.01, P=0.905\right)$. Similarly, thorax length (nest mean Thl) and variation in thorax length within a nest (Thl coefficient of variation) were not associated with the pronotum colour morph frequencies $\left(\mathrm{GLM}_{\mathrm{POISSON}}\right.$, Thl nest mean Thl: $\mathrm{df}=1, \chi^{2}=0.49, P=0.49$; Thl coefficient of variation: $\mathrm{df}=1, \chi^{2}=0.95, P=0.33$ ).

Linear mixed model analyses revealed no associations between nest mate relatedness or complexity of family structure with (a) the richness of the head/thorax colour morph, diversity and evenness; (b) degree of melanisation of head/thorax; (c) head/thorax size (Table 2). Power values varied among the tests between the two types of family structure (Table 2). Weak power was associated with the most non-significant results and high power values with the lowest $P$-values.

\section{DISCUSSION}

In the sample of F. rufa studied we found considerable colony-level variations in relatedness (worker kinship), colour polyphenism, degree of melanisation and individual body size. Some colonies were less colour-polymorphic than the others, containing only two to three head and pronotum colour morphs per colony, while in others there were up to six morphs, varying from the palest to dark-

Table 2. The associations of the average nest mate worker-worker relatedness $(r)$ and family structure (simple when there is one father, complex when there are more than one) with colour morph richness, diversity and evenness, melanisation (MD) and size of the Formica rufa colonies studied in SW Finland. Observed power is added in brackets after the results of between-colony type analyses.

\begin{tabular}{|c|c|c|}
\hline Trait & $r$ & Family structure \\
\hline Head colour morph richness & $F_{1,18}=0.40, P=0.85$ & $F_{1,18}=0.33, P=0.57(0.14)$ \\
\hline Head colour morph diversity & $F_{1,18}^{10}=0.06, P=0.82$ & $F_{1,18}=0.38, P=0.55(0.15)$ \\
\hline Head colour morph evenness & $F_{1,18}=0.47, P=0.50$ & $F_{1,18}=0.43, P=0.52(0.16)$ \\
\hline Pronotum colour morph richness & $F_{1,18}=0.27, P=0.61$ & $F_{1,18}=0.10, P=0.76(0.08)$ \\
\hline Pronotum colour morph diversity & $F_{1,18}=2.30, P=0.15$ & $F_{1,18}=0.46, P=0.51(0.17)$ \\
\hline Pronotum colour morph evenness & $F_{1,18}=0.23, P=0.64$ & $F_{1,18}<0.01, P=0.99(0.05)$ \\
\hline MD of the frons (MDf) & $F_{1,18.6}=0.91, P=0.35$ & $F_{1,18.2}=0.53, P=0.48(0.19)$ \\
\hline MD of pronotum (MDpn) & $F_{1,19}=2.68, P=0.12$ & $F_{1,18.9}=3.16, P=0.09(0.95)$ \\
\hline Head width & $F_{1,19.3}=2.04, P=0.17$ & $F_{1,18.9}=2.32, P=0.14(0.55)$ \\
\hline Thorax length & $F_{1,19.2}=1.03, P=0.32$ & $F_{1,18.7}=2.54, P=0.13(0.56)$ \\
\hline
\end{tabular}


est. The levels of melanisation and size of F. rufa workers also varied between ants from all monodomous colonies. The high within-species phenotypic variability in $F$. rufa revealed in this study is consistent with previous studies on red wood ants and indicates a high degree of phenotypic diversity within and between species (Czechowski \& Douwes, 1996; Stockan et al., 2016). Analyses of this diversity can be even more complicated due to the tendency of species of red wood ant to hybridize (e.g., Sorvari 2006; Korczyńska et al., 2010).

The colour morphs of F. rufa, described for the Finnish population, are based on relatively discrete variations in size and shape of dark melanin-based patterns on the head and pronotum of worker ants (Skaldina \& Sorvari, 2017a). Even though, this type of phenotypic variability is well recognisable and can be detected in other species and castes of red wood ants, it differs from the type of insect colour polymorphism that is supposed to be true (balanced) polymorphism (Simpson et al., 2011). Usually it is produced by a combination of various classes of pigments and structural mechanisms and is strongly associated with life history traits and is genetically preprogramed. For example, such genetically predetermined colour polymorphism (sex dimorphism) is reported in the ant Diacamma sp. (Formicidae: Ponerinae) (Miyazaki et al., 2014). As stressed by Forsman (2016), a clear distinction between continuous variation in colouration and various types of polymorphism is not always possible, as intermediate or transitional forms can appear. Therefore, we consider the melanin-based colour morphs of F. rufa workers as moderately polymorphic. In the case of true polymorphism, a single or several genes regulate the expression of the colour morph. These colour morphs frequently represent alternative strategies in different individuals, varying in life history traits, physiology and behaviour (Forsman et al., 2008). Therefore, polyandrous mothers might produce more colour morph diverse offspring, as, for instance, is reported for the pygmy grasshoppers Tetrix subulata and T. undulata (Forsman et al., 2007). In a previous study (Skaldina \& Sorvari, 2017a), we describe a comprehensive method for accessing and scoring these phenotypic diversities in ecological research. Here we reveal that there is no evidence for an interrelation between phenotypic diversity and the complexity of the structure of the family in F. rufa. Therefore, we consider the variability in the colouration of F. rufa to be a result of polyphenism.

Polyphenism might benefit species in several ways. First, at the population level, negative effects associated with competition are less common in phenotypically diverse groups compared to monomorphic ones (Caesar et al., 2010). Second, species with variable traits are more successful at utilizing resources and tolerant of stress than monomorphic ones (Forsman et al., 2008). Overall, the relative fitness of individuals can differ, depending on morph, even if this is not true (balanced) polymorphism (Forsman, 2016). Therefore, the large phenotypic variability recorded in red wood ants might contribute to their overall fitness and success in different habitats.
Melanisation can also benefit ants at the level of assemblages (Bishop et al., 2016), however, the expression of melanin is in many cases species-specific (Stoehr, 2006). Ants use melanin pigments not only as significant components in their cuticles, which are necessary for hardening and darkening, but also important for thermoregulation and immunity. The key enzyme for melanin production is phenoloxidase, which is present in the cuticle of insects, their mid gut and in their haemolymph (Sugumaran, 2002). Therefore, melanin assists in the physiology of thermoregulation (Trullas et al., 2007; Abe et al., 2013), water balance (True, 2003) and immunity (Armitagae \& Siva-Jothy, 2005; de Souza et al., 2011). Production, maintenance and display of melanised colour traits, either ornamental or not, is in many cases pleiotropically regulated and co-varies with the body condition, however an environmental component to melanisation is more significant for invertebrate than vertebrate animals (Roulin, 2016).

In addition, we failed to find any differences in variation in size between colonies of the red wood ant F. rufa with low and high levels of kinship. Similar results are reported for the desert ant Cataglyphis cursor, in which an increase in genetic diversity does not result in more polymorphic workers and head width does not differ between patrilines (Fournier et al., 2008). Recent reports indicate that F. rufa workers exhibit considerable plasticity in the allometric scaling of relative organ size and cellular-level processes underlying organ construction (Perl \& Niven, 2016). These findings have led to an assumption that red wood ants are highly malleable at the organ and cellular levels and therefore quickly adapt to prevailing environmental conditions. Previously it was shown that colouration in red wood ants depends on size (Skaldina \& Sorvari, 2017a). However, the current results reveal that at the colonial level of organisation, variation in size has no effect on colour variation.

The population studied consisted of a relatively low number of nests $(\mathrm{N}=20)$, thus there is a possibility that the conclusions are not robust. We carried out simple posthoc power analyses of the between group comparisons and the results of the power analyses were variable but show that the $P$-value covary with power. In fact, the $P$-value strongly predicted power values (power fit $r^{2}=0.96$ ). Post hoc power analysis is strongly criticised and the strong dependence on the $P$-value is one of the main arguments against post hoc power analysis (e.g., Jiroutek \& Turner 2018; Zhang et al., 2019). Our hypothesis was that if the traits studied, especially colour morphs are heritable, the single father families should have a lower number of colour morphs than the multiple father families. However, we detected similar frequencies of head colour morphs (Fig. 3A). The morph frequencies of pronotum were visually different between the types of families (Fig. 3B), but do not show the pattern in which the multiple-father families had generally higher numbers of morphs per family (colony). Anyhow, larger sample sizes would have made the interpretation of our results more robust. 


\section{CONCLUSIONS}

If genetic factors affect various phenotypic traits, then closely related individuals might be typically more similar than those with a low degree of kinship. However, neither of the phenotypic traits studied were associated with the average nest mate worker relatedness and differed between colonies with simple and complex family structures. The current results indicate that environmental driving forces might be more significant in determining colouration in red wood ants. However, more sophisticated genetic studies indicating the heritability of phenotypic traits between patrilinies are suggested for the future with the aim to reveal the role of a genetic component in the determination of ant colouration. Comparative studies of the diverse phenotypic traits of organisms with one or more patrilines would provide an opportunity to study the genetic component and in this way genotype-by-environment interactions involved in phenotype construction (Hughes et al., 2003). Studies on the determination of colouration using molecular genetic techniques, especially in non-model organisms, would significantly contribute to evolutionary ecology and reveal genetic or environmental pressures on colouration (Protas $\&$ Patel, 2008). In addition, testing the effect of various environmental factors, such as temperature, humidity, feeding regime and pollution, might contribute to our understanding the role of genotype-by-environment interactions in the phenotypic diversity of red wood ants.

ACKNOWLEDGEMENTS. We thank N. Buzhenina for her valuable assistance with the artwork for the figures. English language editing was performed by the company Lingsoft. This study was financially supported by grants from the Centre for International Mobility (CIMO), the Kuopio Naturalists Society (KLYY) and the Doctoral Programme in Environmental Physics, Health and Biology of the University of Eastern Finland to OS and Emil Aaltonen Foundation to JS.

\section{REFERENCES}

Abe Y., Nishimura T. \& Maeto K. 2013: Causes of polymorphic melanism and its thermoregulatory function in a parasitoid wasp Meteorus pulchricornis (Hymenoptera: Braconidae). Eur. J. Entomol. 110: 627-632.

AhNesjö J. \& Forsman A. 2003: Correlated evolution of colour pattern and body size in polymorphic pygmy grasshoppers, $T e$ trix undulata. - J. Evol. Biol. 16: 1308-1318.

Aljanabi S.M. \& Martinez I. 1997: Universal and rapid saltextraction of high quality genomic DNA for PCR-based techniques. - Nucl. Acids Res. 25: 4692-4693.

Armitage S.A.O. \& Siva-Jothy M.T. 2005: Immune function responds to selection for cuticular colour in Tenebrio molitor. Heredity 94: 650-656.

Bargum K., Boomsma J.J. \& Sundström L. 2004: A genetic component to size in queens of the ant, Formica truncorum. Behav. Ecol. Sociobiol. 57: 9-16.

Bishop T.R., Robertson M.P., Gibb H., van Rensburg B.J., Braschler B., Chown S.L., Foord S.H., Munyai T.C., Okey I., TshivhandeKano P.G., Werenkraut V. \& Parr C.L. 2016: Ant assemblages have darker and larger members in cold environments. - Glob. Ecol. Biogeogr. 25: 1489-1499.
Caesar S., Karlsson M. \& Forsman A. 2010: Diversity and relatedness enhance survival in colour polymorphic grasshoppers. - PLoS ONE 5(5): e10880, 7 pp.

ChapUisat M. 1996: Characterization of microsatellite loci in Formica lugubris and their variability in other ant species. Mol. Ecol. 5: 599-601.

Chapuisat M. \& Keller L. 2002: Division of labour influences the rate of ageing in weaver ant workers. - Proc. R. Soc. (B) 269: 909-913.

Colwell R.K. 2013: EstimateS: Statistical Estimation of Species Richness and Shared Species from Samples. Ver. 9. URL: http:// purl.oclc.org/estimates.

Czechowski W. \& Douwes P. 1996: Morphometric characteristics of Formica polyctena Foerst. and Formica rufa L. (Hymenoptera, Formicidae) from the Gorce Mts; interspecific and intraspecific variations. - Ann. Zool. 46: 125-141.

DAVIDSON D.W. 1978: Size variability in the worker caste of a social insect (Veromessor pergandei Mayr) as a function of a competitive environment. - Am. Nat. 112: 523-532.

Dekoninck W., Maebe K., Breyne P. \& Hendrickx F. 2015: Polygyny and strong genetic structuring within an isolated population of the wood ant Formica rufa. - J. Hymenopt. Res. 41: 95-111.

De Souza D.J., Devers S. \& Lenorr A. 2011: Blochmannia endosymbionts and their host, the ant Camponotus fellah: cuticular hydrocarbons and melanization. - Comp. Rend. Biol. 334: 737-741.

FedoseEva E.B. 2011: Morphometric characteristics of Formica aquilonia ants in monitoring of their settlements. - Entomol. Rev. 91: 152-168.

FORSMAN A. 2016: Is colour polymorphism advantageous to populations and species? - Mol. Ecol. 25: 2693-2698.

Forsman A., Ahnessö J. \& CAesar S. 2007: Fitness benefits of diverse offspring in pygmy grasshoppers. - Evol. Ecol. Res. 9: $1305-1318$.

Forsman A., Ahnesjö J., Caesar S. \& Karlsson M. 2008: A model of ecological and evolutionary consequences of color polymorphism. - Ecology 89: 34-40.

Fournier D., Battaille G., Timmermans I. \& Aron S. 2008: Genetic diversity, worker size polymorphism and division of labour in the polyandrous ant Cataglyphis cursor. - Anim. Behav. 75: 151-158.

Gyllenstrand N., Gertsch P.J. \& Pamilo P. 2002: Polymorphic microsatellite DNA markers in the ant Formica exsecta. Mol. Ecol. Notes 2: 67-69.

Gyllenstrand N., Seppä P. \& Pamilo P. 2004: Genetic differentiation in sympatric wood ants, Formica rufa and F. polyctena. - Insect. Soc. 51: 139-145.

Heinze J. 2008: The demise of the standard ant (Hymenoptera: Formicidae). - Myrmecol. News 11: 9-20.

Hölldobler B. \& Wilson E.O. 1990: The Ants. The Belknap Press of Harvard University Press, Cambridge, MA, 733 pp.

Hughes W.O.H., Sumner S., Van Borm S. \& Boomsma J.J. 2003: Worker caste polymorphism has a genetic basis in Acromyrmex leaf-cutting ants. - Proc. Nat. Acad. Sci. USA 100: 93949397.

Jaffe R., Kronauer D.J.C., Kraus B.F., Boomsma J.J. \& Moritz R.F.A. 2007: Worker caste determination in the army ant Eciton burchellii. - Biol. Lett. 3: 513-516.

JiROUTEK M.R. \& TURNER J.R. 2018: Why it is nonsensical to conduct retrospective power analyses to conduct a postmortem on your study. — J. Clin. Hypertens. 20: 408-410.

Keller L. \& ReEve H.K. 1994: Genetic variability, queen number, and polyandry in social Hymenoptera. - Evolution 48: 694-704. 
Korczyńska J., Gajewska M., Pilot M., Czechowski W. \& RadCHENKO A. 2010: Genetic polymorphism in "mixed" colonies of wood ants (Hymenoptera: Formicidae) in southern Finland and its possible origin. - Eur. J. Entomol. 107: 157-167.

Kunte K., Zhang W., Tenger-Trolander A., Palmer D.H., Martin A., Reed R.D., Mullen S.P. \& Kronforst M.R. 2014: Doublesex is a mimicry supergene. - Nature 507: 229-232.

Leniaud L., Pearcy M., Taheri A. \& Aron S. 2015: Testing the genetic determination of the soldier caste in the silver ant. Insectes Soc. 62: 517-524.

Libbrecht R., Oxley P.R., Kronauer D.J.C. \& Keller L. 2013: Ant genomics sheds light on the molecular regulation of social organization. - Gen. Biol. 14: 212-219.

Miyazaki S., Okada Y., Miyakawa H., Tokuda G., Cornette R., Kishikawa S., Maekawa K. \& Miura T. 2014: Sexually dimorphic body colour is regulated by sex-specific expression of yellow gene in ponerine ant, Diacamma sp. - PLoS ONE 9(3): e92875, 8 pp.

PAmilo P. 1993: Polyandry and allele frequency differences between the sexes in the ant Formica aquilonia. - Heredity 70: 472-480.

Pamilo P., Seppä P. \& Helanterä H. 2016: Population genetics of wood ants. In Stockan J.A. \& Robinson J.H. (eds): Wood ant Ecology and Conservation. Cambridge University Press., Cambridge, pp. 51-80.

Peakall R. \& Smouse P.E. 2012: GenAlEx 6.5: genetic analysis in Excel. Population genetic software for teaching and research - an update. - Bioinformatics 28: 2537-2539.

Perl C.D. \& Niven J.E. 2016: Colony-level differences in the scaling rules governing wood ant compound eye structure. Sci. Rep. 6: 24204, 8 pp.

Porter S.D. \& TsChInKel W.R. 1985: Fire ant polymorphism (Hymenoptera: Formicidae): factors, affecting workers size. Ann. Entomol. Soc. Am. 78: 381-386.

Protas M.E. \& Patel N.H. 2008: Evolution of coloration patterns. - Annu. Rev. Cell. Devel. Biol. 24: 425-446.

RofF D.A. \& FAIRBAIRN D.J. 2013: The costs of being dark: the genetic basis of melanism and its association with fitness-related traits in the sand cricket. - J. Evol. Biol. 26: 1406-1416.

Rosengren R., Sundström L. \& Fortelius W. 1993: Monogyny and polygyny in Formica ants: the result of alternative dispersal tactics. In Keller L. (ed.): Queen Number and Sociality in Insects. Oxford University Press, Oxford, pp. 308-333.

Ross K.G. \& KelLer L. 1998: Genetic control of social organization in an ant. - Proc. Nat. Acad. Sci. USA 95: 14232-14237.

Roulin A. 2016: Condition-dependence, pleiotropy and the handicap principle of sexual selection in melanin-based colouration. - Biol. Rev. 91: 328-348.

Schwander T.R., Rosset H. \& Chapuisat M. 2005: Division of labour and worker size polymorphism in ant colonies: the impact of social and genetic factors. - Behav. Ecol. Sociobiol. 59: $215-221$.
Schwander T., Lo N., Beekman M., Oldroyd B.P. \& Keller L. 2010: Nature versus nurture in social insect caste differentiation. - Trends Ecol. Evol. 25: 275-282.

Simpson S.J., SwOrd G.A. \& Lo N. 2011: Polyphenism in insects. - Curr. Biol. 21: 738-749.

SkAldina O. \& SoRVARI J. 2017a: Not simply red: colouration of red wood ant Formica rufa (Hymenoptera: Formicidae) is polymorphic, modular and size-dependent. - Eur. J. Entomol. 114: $317-324$.

SKaldina O. \& SoRVARI J. 2017b: Wood ant colouration as an ecological indicator for the level of disturbance in managed coniferous forests. - Ecol. Indic. 2: 444-451.

Skaldina O., Peräniemi S. \& Sorvari J. 2018: Ants and their nests as indicators for industrial heavy metal contamination. - Environ. Pollut. 240: 574-581.

Smith C.R., Anderson K.E., Tillberg C.V., Gadau J. \& Suarez A.V. 2008a: Caste determination in a polymorphic social insect: nutritional, social, and genetic factors. - Am. Nat. 172: 497-507.

Smith C.R., Toth A.L., Suarez A.V. \& Robinson G.E. 2008b: Genetic and genomic analyses of the division of labour in insect societies. - Nature Rev. Gen. 9: 735-748.

SoRVARI J. 2006: Two distinct morphs in the wood ant Formica polyctena in Finland: a result of hybridisation? - Entomol. Fenn. 17: 1-7.

Sorvari J. \& HaKkarainen H. 2009: Forest clear-cutting causes small workers in the polydomous wood ant Formica aquilonia. - Ann. Zool. Fenn. 46: 431-438.

Stockan J.A., Robinson E.J.H., Trager J.C., Yao I. \& Seifert B. 2016: Introducing wood ants. evolution, phylogeny, identification and distribution. In Stockan J.A. \& Robinson J.H (eds): Wood Ant Ecology and Conservation. Cambridge University Press, Cambridge, pp. 51-80.

Stoenr A.M. 2006: Costly melanin ornaments: the importance of taxon? - Funct. Ecol. 20: 276-281.

Sugumaran M. 2002: Comparative biochemistry of eumelanogenesis and the protective roles of phenoloxidase and melanin in insects. - Pigm. Cell Res. 15: 2-9.

TRUE J.R. 2003: Insect melanism: the molecules matter. — Trends Ecol. Evol. 18: 640-647.

Trullas S.C., van Wyk J.H. \& Spotila J.R. 2007: Thermal melanism in ectoterms. - J. Therm. Biol. 32: 235-245.

WeTtERER J.K. 1999: The ecology and evolution of worker sizedistribution in leaf-cutting ants (Hymenoptera: Formicidae). Sociobiology 34: 119-144.

WILSON E.O. 1953: The origin and evolution of polymorphism in ants. - Quar. Rev. Biol. 28: 136-156.

Zhang Y., Hedo R., Rivera A., Rull R., Richardson S. \& Tu XM. 2019: Post hoc power analysis: is it an informative and meaningful analysis? - Gen. Psychiatry 32: e100069, 4 pp.

Received July 9, 2019; revised and accepted December 20, 2019 Published online January 27, 2020 